\title{
Properties and performance of mesoporous activated carbons from scrap tyres, bituminous wastes and coal
}

Beatriz Acevedo ${ }^{a}$, Carmen Barriocanal ${ }^{a, k}$, Iwona Lupul ${ }^{b}$, Grażyna Gryglewicz ${ }^{b}$

a Instituto Nacional del Carbón, INCAR-CSIC, Apartado 73, 33080 Oviedo. Spain

${ }^{b}$ Wrocław University of Technology, Department of Polymer and Carbonaceous Materials, Gdańska 7/9, 50-344 Wrocław, Poland

*Corresponding author. Tel: +34 9851190 90; Fax:+34 9852976 62; e.mail address: carmenbr@incar.csic.es

\section{ABSTRACT}

Tyre wastes and their blends with coal and a bituminous waste material obtained from the benzol distillation column of a by-product section of a coking plant were employed as a precursor for the production of activated carbons (ACs). Pyrolysis up to $850{ }^{\circ} \mathrm{C}$ followed by physical activation with $\mathrm{CO}_{2}$ produced mesoporous carbons with different pore size distributions and surface areas. The surface chemistry of the samples was studied by measuring the point of zero charge $\left(\mathrm{pH}_{\mathrm{pzc}}\right)$ and by temperature programmed desorption (TPD). The activated carbons obtained contained higher amounts of basic functional groups. Their textural and surface chemistry characteristics make them highly suitable for adsorbing acid dyes of large molecular size, such as Congo red. The adsorption kinetics was found to conform closely to the pseudo-second-order kinetic model. To determine the adsorption mechanism, the kinetic data were also analysed using the Weber and Morris intraparticle diffusion model and the Boyd model to distinguish between the pore and film diffusion steps. The equilibrium isotherms were of the Langmuir isotherm type. The efficiency of the low-cost ACs prepared for the removal of Congo red dye was similar to that reported in the literature for coal-based ACs and greater than that of other low-cost ACs.

Keywords: Scrap tyres, activated carbons, surface chemistry, adsorption kinetics, Congo Red. 


\section{Introduction}

Effluents from the textile, plastic, food, cosmetics or paper industries contain dyes that need to be removed to avoid water contamination. The chemicals present in the waste range from organic to polymers or inorganic compounds. In addition even very low concentrations of dyes are visible and therefore need to be eliminated. Dyes are non-biodegradable or photodegradable. Moreover the decolouration of textile dye effluents does not occur when treated aerobically by municipal sewerage systems, and some are known to be carcinogenic and mutagenic. These industries consume an enormous amount of water that needs to be treated, posing a serious economic and environmental problem. Although activated carbons may be used to treat these effluents, the cost of such adsorbents is high. Hence there is a need to find low-cost sorbents from wastes [1-4]. The wastes used so far to prepare what are often referred to as "unconventional" adsorbents include coir pitch [5], fly ashes [6,7], orange peel [8], sawdust [9-11], palm shell [12], rice husk [9,13,14], etc.

The porous structure of activated carbons is the principal physical characteristic that will determine their performance as adsorbents. In addition the presence of surface groups containing heteroatoms will confer different chemical properties that will decide their final application. The polarity, solubility and molecular size of the adsorbate and the $\mathrm{pH}$ of the solution are other important factors that need to be taken into account when assessing the effectiveness of an adsorbent [15]. There are many structural varieties of dyes that can be classified as either cationic, nonionic or anionic. This is one of the reasons why it is important to study the surface chemistry of the activated carbons used to eliminate them.

In addition the economic and environmental problems associated with the generation of scrap tyres (End-of-Life-Tyres, ELTs) are increasing due to the enormous generation of such wastes. Pyrolysis is considered as an optimal and environmentally friendly method for the thermo-chemical conversion of wastes such as tyres. Three products can be obtained from pyrolysis: gas with a high calorific value, pyrolytic oil that can be used as fuel and as a source of benzene, toluene, xylene (BTX) or limonene and char that can be used as fuel, adsorbent or carbon black [16-21]. In order to obtain products with a high percentage of 
carbon and a low ash content, co-pyrolysis with coal or bituminous wastes is a good option [22-24]. The co-processing of tyre crumbs with coal has been studied as a way to improve coal liquefaction and hydro-pyrolysis [22, 23, 25, 26]. However until now little work has been carried out on the co-pyrolysis of tyre wastes (reinforcing fibre and tyre crumbs) with coal or with a bituminous waste [24].

The objective of the present study is to investigate the mechanism of the adsorption of Congo Red dye by activated carbons that present different porous textures and surface chemistry characteristics and were prepared from blends of two tyre wastes with coal and a bituminous residue.

\section{Materials and Methods}

\subsection{Materials}

Three components are derived from the grinding of scrap tyres: tyre crumbs, reinforcing fibre and steel. In the present study tyre crumbs and reinforcing fibre were used to prepare five tyre waste - based activated carbons (ACs).

The activated carbons were obtained by means of pyrolysis in a rotary oven as explained in a previous paper [23] followed by physical activation carried out in the rotary oven at $850^{\circ} \mathrm{C}$ with a flow of $250 \mathrm{ml} / \mathrm{min}$ of $\mathrm{CO}_{2}$ to a burn-off of $65 \pm 5 \%$. The wastes used as raw materials for the production of the ACs were: Tyre crumbs (TC) and reinforcing fibres (RF) derived from grinding End-of-Life-Tyres (ELTs), 1:1 blends of TC and RF with a low rank coal, and 1:1 blends of RF with a bituminous waste material (BWM).

The activated carbons (ACs) were milled and sieved to $<0.100 \mathrm{~mm}$ for the elemental and proximate analyses and to between $0.5-0.1 \mathrm{~mm}$ for the adsorption analysis.

Ash content was determined following the ISO1171 standard procedure. The elemental analysis was carried out using a LECO CHN-2000 instrument for $\mathrm{C}, \mathrm{H}$ and $\mathrm{N}$ analysis, a LECO S-144 DR device for sulphur analysis and a LECO VTF-900 instrument for direct oxygen determination. 
The Congo Red anionic acid dye (CR) is commonly used in the textile industry to confer a red color. The physical properties of this dye are listed in Table 1.

\subsection{Textural characterization}

The textural properties of the ACs were studied by means of $\mathrm{N}_{2}$ adsorption at $77 \mathrm{~K}$ on a Micromeritics ASAP 2420 apparatus. The software package provided with the equipment was used to determine the BET surface area $\left(\mathrm{S}_{\mathrm{BET}}\right)$ and the total pore volume $\left(\mathrm{V}_{\mathrm{T}}\right)$ at $\mathrm{p} / \mathrm{p}_{0}=0.96$. The micropore volume $\left(\mathrm{V}_{\mathrm{DR}, \mathrm{N} 2}\right)$ was determined by applying the DubininRadushkevich (D-R) equation to the lower relative pressure zone of the isotherm. The mesopore volume $\left(\mathrm{V}_{\text {meso }}\right)$ was calculated by subtracting the micropore volume from the total pore volume $\left(\mathrm{V}_{\mathrm{T}}\right)$. The average width of the micropores $\left(\mathrm{L}_{0, \mathrm{~N} 2}\right)$ of the ACs was calculated following the procedure of Stoeckli [27]. The Kelvin condensation theory was employed to examine the mesopore volume distribution [28]. The mesopore fraction was expressed as the ratio of the mesopore volume to the total pore volume $\left(\mathrm{V}_{\text {meso }} / \mathrm{V}_{\mathrm{T}}\right)$.

The samples (approximately $0.25 \mathrm{~g}$ ) were degasified under vacuum at $200{ }^{\circ} \mathrm{C}$ for 12 h prior to $\mathrm{N}_{2}$ adsorption to eliminate any moisture and condensed volatiles. The IUPAC pore size classification that assigns a size of $2-50 \mathrm{~nm}$ to mesopores and a size $<2 \mathrm{~nm}$ to micropores was used.

\subsection{Surface chemistry}

The $\mathrm{pH}$ at which the sorbent surface charge has a zero value, is referred to as the point of zero charge $\left(\mathrm{pH}_{\mathrm{pzc}}\right)$. At this $\mathrm{pH}$, the charge of the positive surface sites is equal to that of the negative ones.

The point of zero charge determines the surface charge of the sorbent at a given $\mathrm{pH}$ and this information reveals the possible electrostatic interactions between the sorbent and chemical species [29]. The $\mathrm{pH}_{\mathrm{PzC}}$ of the ACs was determined according to the procedure described by Moreno-Castilla et al. [30].

TPD analyses were carried out in an Autochem II apparatus (Micromeritics). The samples were heated at a constant heating rate of $10^{\circ} \mathrm{C} / \mathrm{min}$ up to $1000^{\circ} \mathrm{C}$ under a $\mathrm{He}$ flow 
of $50 \mathrm{~cm}^{3} / \mathrm{min}$. The desorbed gases were monitored using an Omnistar (Pfeiffer Vacuum) mass spectrometer.

\subsection{Adsorption test}

In order to determine the equilibrium time, adsorption experiments were carried out by shaking $50 \mathrm{mg}$ of adsorbent mixed with $100 \mathrm{~cm}^{3}$ of dye solution in a concentration of 50 $\mathrm{mg} / \mathrm{dm}^{3}$ at $25^{\circ} \mathrm{C}$ in an orbital shaker.

The concentration of the dye was measured using a U-2800A, Hitachi UV-Vis spectrophotometer at a wavelength $497 \mathrm{~nm}$. A digital pH meter (Mettler Toledo) with a glass electrode was employed to measure the $\mathrm{pH}$ before and after contact.

Lagergren pseudo-first-order and pseudo-second order models and the intraparticle diffusion model were applied to describe the CR adsorption process.

The Lagergren pseudo-first order model can be described by Equation (1), and pseudo-second order model by Equation (2).

$$
\begin{gathered}
\frac{d q}{d t}=k_{1}\left(q_{e}-q\right) \\
\frac{d q}{d t}=k_{2}\left(q_{e}-q\right)^{2}
\end{gathered}
$$

Upon integration, Equations (1) and (2) may be written as:

$$
\begin{gathered}
q=q_{e}\left(1-e^{-k_{1} t}\right) \Rightarrow \log \left(q_{e \exp }-q_{t}\right)=\log q_{e}-\left(k_{1} t\right) / 2.303 \\
q=\frac{k_{2} q_{e}^{2} t}{1+k_{2} q_{e} t} \Rightarrow t / q_{t}=1 /\left(k_{2} q_{e}^{2}\right)+t / q_{e}
\end{gathered}
$$

where $t$ and $q_{t}$ are, respectively, time ( $\min$ ) and the amount of dye adsorbed by carbon at time $\mathrm{t}(\mathrm{mg} / \mathrm{g}) ; q_{e \text { exp }}$ and $q_{e}$ are the amount of dye adsorbed at equilibrium-experimental data and equilibrium-calculated data, respectively, expressed as $\mathrm{mg} / \mathrm{g}$ sample; and $k_{1}$ and $k_{2}$ are the first $(1 / \mathrm{min})$ and second $(\mathrm{g} / \mathrm{mg} \mathrm{min})$ order rate constants of adsorption. From the graph of $\log \left(q_{e \exp }-q_{t}\right)$ vs. $t, k_{1}$ and $q_{e}$ were calculated using Equation (3). In the case of the 
pseudo-second order model $k_{2}$ and $q_{e}$ can be obtained from the graph of $t / q$ vs. $t$, Equation (4).

The Weber and Morris intraparticle diffusion model was also used since most adsorption processes can be described with Equation (5) [31]. This model considers intraparticle diffusion as a rate limiting step.

$$
q_{t}=k_{p} \cdot t^{1 / 2}+C
$$

where $q_{t}$ is the amount adsorbed at time $t(\mathrm{mg} / \mathrm{g}), t^{1 / 2}$ is the square root of the time and $k_{p}$ is the rate constant of intraparticle diffusion $\left(\mathrm{mg} / \mathrm{g} \mathrm{min}^{1 / 2}\right), C$ is the intercept which is related to boundary layer thickness.

In order to gain a better knowledge of the adsorption mechanism, the kinetic data were also analysed by means of the Boyd model [32] as follows:

$$
\begin{aligned}
& B_{t}=-0.4977-\ln (1-F) \\
& B_{t}=\left(\sqrt{\pi}-\sqrt{\pi-\left(\frac{\pi^{2} F}{3}\right)}\right)^{2}
\end{aligned}
$$

where $B_{t}$ is function of $F$ and $F$ represents the fraction of solute adsorbed at a time $t$. Equation (6) was used when $\mathrm{F}>0.85$ and Equation (7) when $\mathrm{F}<0.85$.

To determine the adsorption isotherm, various amounts of absorbent with the same volume $\left(100 \mathrm{~cm}^{3}\right)$ of $\mathrm{CR}$ solution $\left(50 \mathrm{mg} / \mathrm{dm}^{3}\right)$ were used. Thus, $0.0075-0.1 \mathrm{~g}$ amounts of activated carbon were introduced into flasks which were agitated until equilibrium was reached. Moreover, a blank solution was used to check the adsorption of the sorbate on the walls. After equilibrium had been reached, the concentration of the dye and the $\mathrm{pH}$ of the solution were measured. Langmuir and Freundlich models were employed to measure the adsorption capacity of the adsorbent by means of Equation (8) and Equation (9) respectively.

$$
q_{e}=\frac{\left(b \cdot q_{\max } C_{e}\right)}{\left(1+b \cdot C_{e}\right)}
$$




$$
q_{e}=K_{f} C_{e}^{1 / n}
$$

where $q_{e}$ is the concentration of CR on the adsorbent $(\mathrm{mg} / \mathrm{g}), C_{e}$ is concentration of $\mathrm{CR}$ at equilibrium in solution $\left(\mathrm{mg} / \mathrm{dm}^{3}\right), q_{\max }$ is the monolayer capacity of the adsorbent $(\mathrm{mg} / \mathrm{g}), b$ is the Langmuir adsorption constant which is related to the energy of adsorption $\left(\mathrm{dm}^{3} / \mathrm{g}\right), K_{f}$ is the Freundlich constant $\left(\mathrm{mg}^{1-n} \mathrm{dm}^{3} \mathrm{n} / \mathrm{g}\right)$ and $1 / n$ is the heterogeneity factor of the Freundlich model which characterizes this heterogeneous system. The model used also describes reversible adsorption and is not restricted to the formation of monolayers.

\section{Results and discussion}

\subsection{Textural and surface chemistry characterization}

The elemental composition and ash contents of the activated carbons are presented in Table 2. All of the samples had a high $\mathrm{C}$ value. However, these carbons had high sulfur and ash contents. In general, a high ash content is a drawback in adsorption applications since the capacity of the adsorbent is considerably reduced [33]. The addition of coal and BWM was observed to produce an increase in $\mathrm{C}$ and a decrease in the $\mathrm{S}$ and ash content of the ACs.

The results relating to the porous texture are shown in the Table 3 and Figure 1. It can be seen that the $S_{B E T}$ values extend over a wide range: between $208-991 \mathrm{~m}^{2} / \mathrm{g}$. The use of coal in the preparation of the ACs increases the surface area. The lowest $S_{B E T}$ value was obtained for the AC carbon prepared from the blend of RF and the BWM. The total pore volume was around $0.5 \mathrm{~cm}^{3} / \mathrm{g}$ except for RF/BWM. The ACs prepared were characterized by a high mesopore volume, with the exception of RF/coal and RF/BWM. However, the contribution of the mesopores to the total pore volume in the $\mathrm{AC}$ prepared from the RF/BWM blend was 0.49 which is as high as that of the other samples except for the RF/coal blend.

The pore volume distribution is shown in Figure 1. The two samples prepared from the blends containing coal (especially RF/Coal) have a high micropore volume. The highest 
mesopore volume corresponds to the sample prepared from TC. It should be noted that in all prepared ACs the mesopore distributions were mainly in the $10-50 \mathrm{~nm}$ range.

The pore structure of the ACs prepared in the present research work is different to that of most commercial grade carbons, which are mainly microporous. However, the high mesoporosity of most tyre-derived samples is an advantage for the adsorption of large molecular-size compounds from solution like Congo Red dye [34,35]. Congo Red dye consists of large molecules with a width of $2.62 \mathrm{~nm}$ and a molecular weight (MW) of 650.7 $\mathrm{g} / \mathrm{mol}$ (Table 1). Therefore, in spite of having the highest surface area the RF/Coal blend may experience more difficulty in adsorbing Congo Red than the other samples due to its microporous nature.

The combination of a high surface area and an appropriate pore size distribution is a necessary precondition for using activated carbon as an adsorbent for a particular application. However, the nature and the amount of surface groups of the activated carbons must also be taken into account. In fact, although the sites associated with the surface functional groups represent a very small proportion of the surface area, small variations in their chemical nature can produce significant changes in the adsorption capacity of ACs. Functional groups mainly affect the hydrophobic / hydrophilic and acidic / basic character of ACs [33].

The characterization of the surface chemistry of ACs is not an easy task to perform. Thus to study these activated carbons, two techniques widely used $[36,37]$ in research related to the surface chemistry of adsorbents were employed: temperature-programmed desorption (TPD) and $\mathrm{pH}_{\mathrm{PZC}}$ analysis.

Table 3 shows the $\mathrm{pH}_{\mathrm{PzC}}$ results. All of the activated carbons had a basic $\mathrm{pH}_{\mathrm{PZC}}$, above 8. The $\mathrm{pH}_{\mathrm{PZC}}$ obtained for $\mathrm{TC}$ was close to the value obtained by Troca-Torrado for the same material $\left(\mathrm{pH}_{\mathrm{PZC}}=8.4\right)[3]$.

The adsorption experiments were performed at a pH of between 6.8 and 7.6. Taking into account the $\mathrm{pK}_{\mathrm{a}}$ of Congo Red shown in Table 1, the CR dye was in the anionic form in this solution. 
Activated carbons with a $\mathrm{pH}_{\mathrm{PzC}}$ higher than the $\mathrm{pH}$ of the solution, have positive surface charges. Therefore there is a strong attraction between the adsorbent and adsorbate molecules [2, 15, 35].

TPD involves heating the carbon in a flowing carrier gas at a programmed heating rate to induce thermal desorption of the adsorbed species from the carbon surface and provides information about the thermal stability of the funtional groups present on the carbon material. Figure 2 shows the $\mathrm{CO}$ (Figure 2.a) and $\mathrm{CO}_{2}$ (Figure 2.b) TPD profiles for all the ACs. The bands displayed in Figure 2 represent the decompostion of specific oxygenated functional groups. Assuming there are no mineral matter effects or diffusional limitations the evolution of $\mathrm{CO}_{2}$ must be related to the presence of acid groups on the adsorbent surface i.e. carboxylic acids, anhydrides and lactones, where $\mathrm{C}$ is bonded to two oxygen atoms [38]. $\mathrm{CO}$ desorption occurs at higher temperatures due to the decomposition of phenols, carbonyl groups, ethers and basic structures such as quinones, chromenes and pyrones (where one C atom is bonded to one oxygen atom) [39-45].

Activated carbons from TC and RF (Figure 2.b) present small peaks at temperatures between $250-500^{\circ} \mathrm{C}$, indicating that these carbons had carboxylic acid groups on their surface. The TC/Coal, RF/Coal and RF/BWM activated carbons show marked peaks at low temperatures with maxima at $198^{\circ} \mathrm{C}, 190^{\circ} \mathrm{C}$ and $275^{\circ} \mathrm{C}$. These peaks correspond to strong carboxylic acids, while the peaks at higher temperatures $\left(385,365\right.$ and $378{ }^{\circ} \mathrm{C}$ for TC/Coal, RF/Coal and RF/BWM, respectively) correspond to weak carboxylic acids [39, 46, 47].

However, the amount of carboxylic acid groups was not high compared to that of the other surface oxygen functionalities, since gas phase oxidation increased the number of lactone, phenol and carbonyl/quinone surface groups [41].

The $\mathrm{CO}_{2}$ evolution profiles show sharp peaks at around $600^{\circ} \mathrm{C}$ that can be assigned to different components: between $550-600^{\circ} \mathrm{C}$ to peroxides, at $631-822^{\circ} \mathrm{C}$ to lactones and the peak at around $650^{\circ} \mathrm{C}$ to decomposition of mineral matter [39,45 47,49$]$. 
The peak at around $400^{\circ} \mathrm{C}$ on the $\mathrm{CO}$ curves (Figure 2.a) in ACs prepared from TC and at 269 and $371^{\circ} \mathrm{C}$ on the curve from RF/BWM, is asso ciated to the decomposition of $\alpha$ substituted ketones and / or aldehydes [47]. The presence of phenol is also possible given the increase in the $\mathrm{CO}$ signal in the $650-725^{\circ} \mathrm{C}$ range. In the $800-950{ }^{\circ} \mathrm{C}$ temperature range, the curve corresponding to the $\mathrm{CO}$ evolution shows a peak at around $800{ }^{\circ} \mathrm{C}$ which corresponds to carbonyl groups in quinone structures [39, 41, 44, 45]. Moreover, the shape of the curves (Figure 2.a) indicates that at higher temperatures more $\mathrm{CO}$ was detected which is indicative of the presence of chromenes and pyrones. The basic character of these ACs is associated with the presence of oxygen-containing surface groups at the edge of carbon crystallites such as carbonyls, pyrone and chromene-type structures [38].

Table 4 contains the data related to the amount of $\mathrm{CO}$ and $\mathrm{CO}_{2}$ evolved during the TPD experiments expressed as $\mu \mathrm{mol} / \mathrm{g}$ of activated carbon. The amount of oxygen determined by TPD was also included together with the ratio between the amount of $\mathrm{CO}$ and $\mathrm{CO}_{2}$ evolved during the experiments. Taking into account that $\mathrm{CO}$ is produced mainly due to the decomposition of basic compounds and that the $\mathrm{CO} / \mathrm{CO}_{2}$ ratio is greater than 2 in all these cases, the surface characteristics of the ACs as determined by TPD exhibit a basic character. These findings are in agreement with the $\mathrm{pH}_{\mathrm{PzC}}$ results.

\subsection{Equilibrium time}

The adsorption of CR on the ACs was studied using the same CR concentration in all cases $(50 \mathrm{mg} / \mathrm{dm} 3)$. The results of adsorption of $\mathrm{CR}$ with time are presented in Figure 3 expressed as the amount of CR adsorbed ( $\mathrm{q}, \mathrm{mg} / \mathrm{g}$ ) as a function of time. An increase in the adsorption time implies an increase in the removal of CR before equilibrium was achieved.

However, the time needed to reach equilibrium and the percentage of CR removed from solution showed great variations as can be seen from Table 5. The shortest equilibrium time corresponds to the ACs prepared from TC and RF which did not need a long time to reach equilibrium. This may be due to the large contribution of mesopores (Table 3). In the case of the ACs prepared from the blends that included coal (i.e. TC/Coal and RF/Coal) the time 
required to reach equilibrium were too high since values increased to values higher than 80 $\mathrm{h}$ min even though they had a higher surface area (SBET). The highest equilibrium time corresponds to the $\mathrm{AC}$ prepared from the RF/Coal blend whose mesopore volume contribution to the total pore volume is the lowest (see Table 3), despite having the highest surface area. Also to be noted is the fact that the AC prepared from the RF/BWM blend has an equilibrium time similar to that of RF and it has a very low surface area but its mesopore contribution to the total pore volume is not the lowest. The use of coal for the preparation of ACs produces an increase in the micropore volume (Figure 1) which leads to an increase in the time required to reach equilibrium. The percentage of $\mathrm{CR}$ removed from solution, as shown in Table 5, is related to its pHPZC. Due to the acidic character of $\mathrm{CR}$, the higher the point of zero charge is, the higher the percentage of CR removal after equilibrium has been reached. $\mathrm{RF}$ with a $\mathrm{pH}_{\mathrm{PZC}}$ of 9.5 showed the highest percentage of dye removal $(98 \%)$ whereas $\mathrm{RF} / \mathrm{Coal}$ with a $\mathrm{pH}_{\mathrm{PZC}}$ of 8.2 gave rise at the lowest percentage of dye removal (81\%).

The nature of the adsorption process depend on physical or chemical characteristics of the adsorbent system and also on the system conditions. To describe the mechanism of adsorption from aqueous solutions, attention needs to be focussed principally on the rate limiting step. Numerous kinetic models mentioned in the literature can be applied [50]. In the present study, the Lagergren first order and pseudo-second order kinetic equations were used to describe the $\mathrm{CR}$ adsorption process [2, 5, 51]. Reaction kinetic equations give the empirical rate constant which makes it possible to compare the adsorption kinetics of different adsorbents.

The calculated rate constants and correlation coefficients are shown in Table 6. The correlation coefficients of the first order model were sometimes very low and the difference between the values of $q_{e \text { exp }}$ and the calculated values $\left(q_{e}\right)$ are significant. The second-order kinetic model gave a better fit, the correlation coefficients were higher and the $q_{e}$ values were closer to the experimental ones than those calculated by applying the first order model except in the case of the RF/Coal adsorbent. However, the correlation coeficients were not 
as good as others found in the literature for the adsorption of CR on mesoporous activated carbons $[5,35]$. The plots of the linearized form of the second-order kinetic model for the adsorption of CR on different samples are shown in Figure 4 where it can be seen that the pseudo-second order kinetic model provided a good correlation for the adsorption of Congo red.

The mechanism of Congo red removal from aqueous phase by adsorption is assumed to consist of various steps: migration of the CR dye molecules from the bulk solution to the surface of the sorbent, diffusion through the boundary layer to the surface of the sorbent, intraparticle diffusion into the interior of the sorbent and adsorption on the solid surface $[51,52]$. The solid/liquid adsorption process is controlled by the slowest step. The solute transfer is usually characterized by either boundary layer diffusion or intraparticle diffusion or both.

It is widely accepted that the adsorption rate of an adsorbate during adsorption onto a porous material is affected by mass transfer phenomena. As the above kinetic models were not able to identify the diffusion mechanism, the intraparticle diffusion model based on the theory proposed by Weber and Morris was applied [31]. Intraparticle diffusion is a typical rate limiting step in adsorption on porous adsorbents $[50,53]$. In general, the plot of $q_{t}$ vs. $t^{1 / 2}$ is multilinear, which indicates that two or more steps occur in the adsorption process. In the case of adsorbents with micro-, meso- and macropores, up to three linear sections are obtained [50].

Figure 5a shows the intraparticle diffusion plots for adsorption of Congo red on the prepared ACs. The plots were fitted using the linear regression method. Only in the case of TC does the plot show a linear straight line passing through the origin, which suggests that intraparticle diffusion is the only rate-controlling step in the adsorption of CR. This finding is supported by the highly developed mesoporosity of the material. TC has a very high mesopore volume $\left(0.414 \mathrm{~cm}^{3} / \mathrm{g}\right)$ and its mesopore contribution to the porous texture is also very high (0.7). 
Both external diffusion and the intraparticle diffusion contribute to the whole adsorption process in RF, RF/Coal and RF/BMW. As can be seen in Figure $5 a$, their $q_{t} v s . t^{1 / 2}$ plots consist of two linear portions. The first linear portion stage is attributed to CR diffusion into the pores of the adsorbent. The second linear portion represents the final equilibrium step where intraparticle diffusion starts to slow down due to the very low adsorbate concentration left in the solution. The extent of deviation from the origin of the first linear portions indicates that the largest boundary layer thickness corresponds to RF. The competitive adsorption of water on the basic surface of $\mathrm{RF}\left(\mathrm{pH}_{\mathrm{PZC}}=9.5\right.$, see Table 3$)$ helps to explain the greater bounday layer effect in the case of adsorption on RF [54].

Furthermore, to gain a deeper insight into the adsorption mechanism and to distinguish between the pore and boundary layer diffusion steps involved in the adsorption process the Boyd model was applied to the kinetic data (Figure 5b) [32, 55]. Only in the case of $\mathrm{RF}$ does the $\mathrm{B}_{\mathrm{t}}$ versus $t$ plot not pass through the origin indicating that boundary layer diffusion is the slowest step in the adsorption. These results are in agreement with those obtained with the Webber and Morris model.

In the case of TC/Coal adsorption process consisted of three steps. The removal of Congo red was rapid in the initial period of contact time after which it gradually slowed down. That is: it stopped with the increase in contact time. The CR molecules first entered the macropores and wider mesopores, and after that, more slowly, the smaller mesopores and wide micropores. This implies that intraparticular diffusion into the smaller mesopores and micropores is the rate-limiting step for the TC/Coal.

The RF/Coal has the smallest slope in the first portion of the plots which suggests that it has the slowest intraparticle diffusion rate. This can be explained by microporous character of the material (Table 3). The RF/Coal is characterized by highly developed microporosity $\left(0.370 \mathrm{~cm}^{3} / \mathrm{g}\right)$ and a low fraction of mesopores $(0.21)$. It was at this stage that TC showed the fastest rate of adsorption due to the high mesopore volume and high mesopore contribution to the porous texture. 


\subsection{Equilibrium Isotherms}

Because the optimization of ACs as adsorbents is of primary importance, the adsorption isotherms were studied in some depth. Adsorption isotherm models describe the manner in which molecules of an absorbate interact with the surface of the adsorbent. The kinetics of the process is essential to understanding the mechanism of the adsorption. The experimental adsorption isotherms for CR in the five AC samples are plotted in Figure 6.

The literature has reported numerous models that explain the results obtained from adsorption isotherms [5]. In this study, the Langmuir and Freundlich models were chosen because the equilibrium isotherms obtained appeared to be mostly of the Langmuir isotherm type [56]

The TC and RF isotherms reflect a large amount of dye adsorption at equilibrium at high adsorbate concentrations. The shape of the isotherms is of the L-type, i.e. of the Langmuir type. The Langmuir isotherm indicates that the adsorbent's surface is covered by a monolayer of molecules and that they are in a horizontal position. It also assumes that the adsorbent is structurally homogeneous and that all the sorption sites are identical and energetically equivalent [57]. The shape of the curves corresponding to TC/Coal, RF/Coal and RF/BWM fit the Langmuir model.

The values of the Langmuir and Freundlich parameters are shown in Table 7. The correlation coefficients of the linearized form of both equations indicate that the Langmuir model provides a better fit for all the samples. The highest value for the Langmuir monolayer capacity $\left(q_{\max }\right)$ corresponds to the adsorbent prepared from RF. As mentioned above RF has the highest $\mathrm{pH}_{\mathrm{PZC}}$ value, though not the highest mesopore pore volume. In general, the highest $V_{\text {meso }} / V_{T}$ ratio corresponds to the adsorbents with the highest monolayer capacity. Monolayer capacity is also related to the $\mathrm{pH}_{\mathrm{PZC}}$. Thus, the higher the point of zero charge is the higher the adsorption capacity of the CR acid dye. RF/Coal exhibits a reasonable adsorption capacity despite its microporous texture. This suggests that large micropores also contribute to the adsorption of CR. 
The results of $\mathrm{q}_{\max }$ obtained for the adsorption of $\mathrm{CR}$ on the adsorbents prepared from waste tyres were similar to those reported in the literature for coal-based ACs (52-189 $\mathrm{mg} / \mathrm{g}$ ) [35]. Adsorbents prepared with other materials like coir pith, and orange peel showed considerably lower $q_{\max }$ values: 6.72 and $22.44 \mathrm{mg} / \mathrm{g}[5,8]$.

\section{Conclusions}

Activated carbons prepared from tyre wastes have been successfully used to adsorb Congo Red dye. The mesopore volume of the samples was between 0.078 and 0.414 $\mathrm{cm}^{3} / \mathrm{g}$. The high mesopore contribution to the total pore volume $(0.49-0.70)$ and wide microporosity make these pores easily accessible of large-molecular size dyes. The $\mathrm{pH}_{\mathrm{PZC}}$ of the activated carbons was over 8 , and the TPD experiments showed that most of the functional groups present on the surface of the ACs were basic, which will facilitate the adsorption of $\mathrm{CR}$ anions. The best results were obtained for $\mathrm{RF}$ which had a $\mathrm{V}_{\text {meso }} / \mathrm{V}_{\mathrm{T}}$ of 0.62 and $\mathrm{p} \mathrm{pH}$ PzC of 9.5 .

The time required for equilibrium to be reached in all five ACs was found to be dependent on the texture and the presence of mesopores, the latter facilitating the access of high molecular size adsorbates to the porous structure of the adsorbent. A good correlation was obtained between the experimental data recorded and a pseudo secondorder kinetic model. However, intraparticle diffusion plays an important role in adsorption on porous adsorbents. For all tested ACs the intraparticle diffusion was the rate limiting step in the adsorption process. Except in the case of TC, the boundary layer diffusion also affected the adsorption of CR especially in RF. The Boyd model confirmed the importance of the boundary layer diffusion in the case of RF.

The Langmuir theory explains the results of the adsorption equilibrium isotherms better than the Freundlich model with correlation coefficients in the $0.965-0.999$ range.

\section{Ackowledgements}


The research leading to these results has received funding from the Spanish MICINN project reference CTM2009-10227. BA thanks the Government of the Principado de Asturias for the award of a predoctoral grant with funds from PCTI-Asturias. This work was also supported by a statutory activity subsidy from the Polish Ministry of Science and Higher Education for the Faculty of Chemistry of Wrocław University of Technology.

\section{References}

[1] Crini G. Non-conventional low-cost adsorbents for dye removal: A review. Bioresource Technol 2006; 97: 1061-1085.

[2] Purkait MK, Maiti A, DasGupta S, De S. Removal of congo red using activated carbon and its regeneration. J. Hazard. Mat. 2007; 145: 287 - 295.

[3] Troca-Torrado C, Alexandre-Franco M, Fernández-González C, Alfaro-Domínguez M, Gómez-Serrano V. Development of adsorbents from used tire rubber. Their use in the adsorption of organic and inorganic solutes in aqueous solution. Fuel Process. Technol. 2011; 92: 206 - 212.

[4] Chang OS, Cheung WH, McKay G. Single and multicomponent acid dye adsorption equilibrium studies on tyre demineralised activated carbon. Chem. Eng. J. 2012; 191: $162-170$.

[5] Namasivayam C, Kavitha D. Removal of Congo Red from water by adsorption onto activated carbon prepared from coir pitch, an agricultural solid waste. Dyes Pigments 2002; $54: 47$ - 58.

[6] Ahmaruzzaman M. A review on the utilization of fly ash. Prog. Energ. Combust. 2010; 36: 327-363.

[7] Sun D, Zhang X, Wu Y, Liu X. Adsorption of anionic dyes from aqueous solution on fly ash. J. Hazard. Mater. 2010; 181: 335 - 342.

[8] Namasivayam C, Muniasamy N, Gayatri K, Rani M, Ranganathan K. Removal of dyes from aqueous solutions by cellulosic waste orange peel. Bioresour. Technol. 1996; 57: 37- 43.

[9] Malik PK. Use of activated carbons prepared from sawdust and rice-husk for adsorption of acid dyes: a case study of acid yellow 36. Dyes Pigments 2003; 56: 239 - 249.

[10] Özacar M, Sengil Al. Adsorption of metal complex dyes from aqueous solutions by pine sawdust. Bioresour. Technol. 2005; 96:791 - 795.

[11] Khattri SD, Singh MK. Use of sagaun sawdust as an adsorbent for the removal of crystal violet dye from simulated wastewater. Environ. Prog. Sustain. Energy 2012; 31: 435-442. 
[12] Sreelatha G, Kushwaha S, Rao V J, Padmaja P. Kinetics and equilibrium studies of adsorption of anionic dyes using acid-treated palm shell. Ind. Eng. Chem. Res. 2010; 49: 8106 - 8113.

[13] Guo Y, Yang S, Fu W, Qi J, Li R, Wang Z, Xu H. Adsorption of malachite green on micro- and mesoporous rice husk-based active carbon. Dyes Pigments 2003; 56: $219-229$.

[14] Mohamed MM. Acid dye removal: comparison of surfactant modified mesoporous FSM16 with activated carbon derived from rice husk. J. Colloid Interf. Sci. 2004; 272: 28 34.

[15] Radovic LR, Moreno-Castilla C, Rivera-Utrilla J. Carbon Materials as Adsorbents in Aqueous Solutions. In: Radovic LR, Editor. Chemistry and Physics of Carbon, Vol. 27, New York: Marcel Dekker; 2001,p. 227-405.

[16] Amari T, Themelis NJ, Wernick IK. Resource recovery from used rubber tires. Resources Policy 1999; 25: 179 - 188.

[17] Kyari M, Cunliffe A, Williams V. Characterization of oils, gases and char in relation to the pyrolysis of different brands of scrap automotive tires. Energy Fuels 2005; 19: 1165 - 1173.

[18] Murillo R, Aylón E, Navarro MV, Callén MS, Aranda A, Mastral AM. The application of thermal processes to valorise waste tyre. Fuel Process. Technol. 2006; 87: 143 147.

[19] Fernández AM, Barriocanal C, Alvarez R. Pyrolysis of a waste from the grinding of scrap tyres. J. Hazard. Mater. 2012; 203-204:236 - 243.

[20] ÖnenÇ S, Brebu M, Vasile C, Yanik J. Copyrolysis of scrap tires with oily wastes. J Anal. Appl. Pyrolysis 2012; 94: 184 - 189.

[21] Antoniou N, Zabaniotou A. Features o fan efficient and environmentally attractive used tyres pyrolysis with energy and material recovery. Renew. Sust. Energ. Rev. 2013; 20: 539 - 558.

[22] Mastral AM, Murillo R, Perez-Surio MJ, Callén MS. Coal hydrocoprocessing with tires and tire components. Energy Fuels 1996; 10: 941 - 947.

[23] Acevedo B, Barriocanal C, Álvarez R. Pyrolysis of blends of coal and tyre wastes in a fixed bed reactor and a rotary oven. Fuel 2013; 113: 817-825.

[24] Acevedo B, Barriocanal C. Fuel-oils from co-pyrolysis of scrap tyres with coal and a bituminous waste. Influence of oven configuration. Fuel 2014; 125:155-163.

[25] Mastral AM, Callén S, García T, Navarro MV. Aromatization of oils from coal-tyre cothermolysis II. PAH content study as a function of the process variables. Fuel Process. Technol. 2000; 68: 45 - 55. 
[26] Callén M, Hall V, Mastral AM, García T, Ross A, Bartle KD. PAH presence in oils and tars from coal-tyre coprocessing. Fuel Process. Technol. 2000; 62: 53 - 63.

[27] Stoeckli F. Characterization of microporous carbons by adsorption and immersion techniques. In: Patrick JW, Editor. Porosity in carbons. London: Edward Arnold; 1995, p. 67-92.

[28] Gregg SJ, Sing KSW. Adsorption, Surface Area and Porosity, London: Academic Press; 1997

[29] Fiol N, Villaescusa I. Determination of sorbent point zero charge: Usefulness in sorption studies. Environ. Chem. Lett. 2009; 7: 79 - 84.

[30] Moreno-Castilla C, Lopez-Ramon MV, Carrasco-Marin F. Changes in surface chemistry of activated carbons by wet oxidation. Carbon 2000; 38: 1995 - 2001.

[31] Weber J W J, Morris JC. Kinetics of adsorption on carbon from solution. J. Sanit. Eng. Div. Am. Soc. Civ. Eng. 1963; 89: 31-60.

[32] Boyd GE, Adamson AW Myers JLS. The exchange adsorption of ions from aqueous solutions by organic zeolitesll: kinetics. J. Am. Chem. Soc. 1947; 69:2836-2848.

[33] Bandosz TJ. Activated carbon surfaces in environmental remediation, Interface Science and Technology, Amsterdam: Elsevier; 2006.

[34] San Miguel G, Fowler GD, Dall'Orso M, Sollars CJ. Porosity and surface characteristics of activated carbons produced from waste tyre rubber. J. Chem. Technol. Biotechnol. 2001; 77:1 - 8.

[35] Lorenc-Grabowska E, Gryglewicz G. Adsorption characteristics of Congo Red on coalbased mesoporous activated carbon. Dyes Pigments 2007; 74: 34 - 40.

[36] Faria PCC, Órfao JJM, Pereira MFR. Adsorption of anionic and cationic dyes on activated carbons with different surface chemistries. Water res. 2004; 38: 20432052.

[37] Villacañas F, Pereira MFR, Órfao JJM, Figueiredo JL. Adsorption of simple aromatic compounds on activated carbons. J. Colloid Interf. Sci. 2006; 293: 128-136.

[38] Pereira MFR, Soares SF, Órfão JJM, Figueiredo JL. Adsorption of dyes on activated carbons: influence of surface chemical groups. Carbon 2003; 41: 811 - 821.

[39] Zielke U, Hüttinger KJ, Hoffman WP. Surface-oxidized carbon fibers: I. Surface structure and chemistry. Carbon 1996; 34: 983 - 998.

[40] De la Puente G, Pis JJ, Menéndez JA, Grange P. Thermal stability of oxygenated functions in activated carbons. J. Anal. Appl. Pyrolysis 1997; 43: 125 -138.

[41] Figueiredo JL, Pereira MFR, Freitas MMA, Órfao JJM. Modification of the surface chemistry of activated carbons. Carbon 1999; 37: $1379-1389$. 
[42] Haydar S, Moreno-Castilla C, Ferro-García M A, Carrasco-Marín F, Rivera-Utrilla J, Perrard A, Joly JP. Regularities in the temperature-programmed desorption spectra of $\mathrm{CO}$ and CO from activated carbons. Carbon 2000; 38: 1297 - 1308.

[43] Raymundo-Piñero E, Cazorla-Amorós D, Salinas-Martínez de Lecea C, Linares Solano A. Factors controling the SO removal by porous carbons: relevance of the $\mathrm{SO}_{2}$ oxidation step. Carbon 2000; 38: 335 - 344.

[44] Figueiredo JL, Pereira MFR. The role of surface chemistry in catalysis with carbons. Catal. Today 2010; 150: 2 - 7.

[45] Ania CO. Characterization of the surface chemistry of green carbons. In: Rufford T, Jurkahova D, Zhu J., Editors. Green Carbons: advances and applications, Stanford: PAN Stanford Publications; 2012, p 1 - 26.

[46] Salame II, Bandosz TJ. Surface chemistry of activated carbons: combining the results of temperature-programmed desorption, Boehm and Potentiometric titrations. J. Colloid Interf. Sci. 2001; 240: 252- 258.

[47] Figueiredo JL, Pereira MFR, Freitas MMA, Órfao JJM. Characterization of active sites on carbon catalysis. Ind. Eng. Chem. Res. 2007; 46: 4110 - 4115.

[48] Castro-Muñiz A, Suárez-García F, Martínez-Alonso A, Tascón JMD. Activated carbon fibers with a high content of surface functional groups by phosphoric acid activation of PPTA. J. Colloid. Interf. Sci. 2011; 361: 307 - 315.

[49] Gorgulho HF, Mesquita JP, Gonçalves F, Pereira V, Figueiredo JL. Characterization of the surface chemistry of carbon materials by potentiometric titrations and temperature-programmed desorption. Carbon 2008; 46: 1544 -1555.

[50] Ho YS, Ng JCY, McKay G. Kinetics of pollutant sorption by biosorbents: Review. Separ. Purif. Method. 2000; 29: 189-232.

[51] Dawood S, Sen T K. Removal of anionic dye Congo red from aqueous solution by raw pine and acid-treated pine cone powder as adsorbent: Equilibrium, thermodynamic, kinetics, mechanism and process design. Water res. 2012; 46: 1933 -1946.

[52] Badruzzaman M, Westerhoff $P$, Knappe DR. Intraparticle diffusion and adsorption of arsenate onto granular ferric hydroxide (GFH). Water Research 2004;35 (40024012).

[53] Özcan A S, Özcan A. Adsorption of acid dyes from aqueous solutions onto acidactivated bentonite. J.Colloid Interf. Sci. 2004; 276: 39-46.

[54] Dhaouadi A, Monser L, Adhoum N. Removal of rotenone insecticide by adosrption onto chemically modified activated carbons. J Hazard. Mat. 2010; 181: 692-699.

[55] Foo KY, Hameed BH. Textural porosity, surface chemistry and adsorptive properties of durian shell derived activated carbon prepared by microwave assisted $\mathrm{NaOH}$ activation. Chem. Engineering Journal 2012; 187: 53-62. 
[56] Lin YR, Teng H. Mesoporous carbons from waste tire char and their application in wastewater discoloration. Micropor.mesopor. mat. 2002; 54: 167 - 174.

[57] Langmuir I. The adsorption of gases on plane surfaces of glass, mica and platinum. J. Am. Chem. Soc. 1916; 38: 2221-2295. 
Table 1. Physical properties of Congo Red.

\begin{tabular}{|c|c|}
\hline Molecular Weight (g/mol) & 650.7 \\
\hline Width (nm) & 2.62 \\
\hline Depth (nm) & 0.74 \\
\hline Thickness (nm) & 0.43 \\
\hline pKa & 5.5 \\
\hline
\end{tabular}


Table 2. Elemental and ash analysis of ACs.

\begin{tabular}{lcccccc}
\hline Samples & $\begin{array}{c}\mathrm{C} \\
(\mathrm{wt.} \%, \mathrm{db})\end{array}$ & $\begin{array}{c}\mathrm{N} \\
(\mathrm{wt} . \%, \mathrm{db})\end{array}$ & $\begin{array}{c}\mathrm{S} \\
(\mathrm{wt} . \%, \mathrm{db})\end{array}$ & $\begin{array}{c}\mathrm{H} \\
(\mathrm{wt} . \%, \mathrm{db})\end{array}$ & $\begin{array}{c}\text { O direct } \\
(\mathrm{wt} . \%, \mathrm{db})\end{array}$ & $\begin{array}{c}\text { Ash } \\
(\mathrm{wt} . \%, \mathrm{db})\end{array}$ \\
\hline TC & 57.0 & 0.4 & 4.1 & 0.2 & 1.5 & 37.8 \\
RF & 78.6 & 0.5 & 3.3 & 0.2 & 2.0 & 19.7 \\
TC/Coal & 73.2 & 1.1 & 2.3 & 0.2 & 0.6 & 23.1 \\
RF/Coal & 81.9 & 1.6 & 1.7 & 0.4 & 0.6 & 15.3 \\
RF/BWM & 84.4 & 1.6 & 2.8 & 0.4 & 1.9 & 11.1 \\
\hline
\end{tabular}


Table 3. Textural properties of the ACs prepared and $\mathrm{pH}_{\mathrm{PzC}}$ results..

\begin{tabular}{lccccccc}
\hline Sample & $\begin{array}{c}\mathrm{S}_{\mathrm{BET}} \\
\mathrm{m}^{2} / \mathrm{g}\end{array}$ & $\begin{array}{c}\mathrm{V}_{\mathrm{T}} \\
\mathrm{cm}^{3} / \mathrm{g}\end{array}$ & $\begin{array}{c}\mathrm{V}_{\mathrm{DR}, \mathrm{N} 2} \\
\mathrm{~cm}^{3} / \mathrm{g}\end{array}$ & $\begin{array}{c}\mathrm{L}_{0, \mathrm{~N} 2} \\
\mathrm{~nm}\end{array}$ & $\begin{array}{c}\mathrm{V}_{\text {meso }} \\
\mathrm{cm}^{3} / \mathrm{g}\end{array}$ & $\mathrm{V}_{\text {meso }} / \mathrm{V}_{\mathrm{T}}$ & \\
\hline $\mathrm{TC}$ & 496 & 0.588 & 0.174 & 1.72 & 0.414 & 0.70 & 8.7 \\
$\mathrm{RF}$ & 392 & 0.402 & 0.151 & 1.33 & 0.251 & 0.62 & 9.5 \\
TC/Coal & 840 & 0.596 & 0.292 & 1.55 & 0.304 & 0.51 & 8.3 \\
RF/Coal & 991 & 0.467 & 0.370 & 1.29 & 0.097 & 0.21 & 8.2 \\
RF/BWM & 208 & 0.158 & 0.080 & 1.09 & 0.078 & 0.49 & 8.3 \\
\hline
\end{tabular}


Table 4. Amounts of $\mathrm{CO}$ and $\mathrm{CO}_{2}$ released during the TPD experiments and calculated by integrating the areas under the corresponding peaks.

\begin{tabular}{ccccc}
\hline & $\begin{array}{c}\mathrm{CO} \\
(\mu \mathrm{mol} / \mathrm{g})\end{array}$ & $\begin{array}{c}\mathrm{CO}_{2} \\
(\mu \mathrm{mol} / \mathrm{g})\end{array}$ & $\begin{array}{c}\mathrm{O} \\
(\mu \mathrm{mol} / \mathrm{g})\end{array}$ & $\mathrm{CO} / \mathrm{CO}_{2}$ \\
\hline $\mathrm{TC}$ & 104 & 36 & 176 & 2.9 \\
$\mathrm{RF}$ & 223 & 94 & 410 & 2.4 \\
$\mathrm{TC} /$ Coal & 111 & 22 & 155 & 5.0 \\
RF/Coal & 140 & 40 & 220 & 3.5 \\
RF/BWM & 131 & 41 & 214 & 3.2 \\
\hline
\end{tabular}


Table 5. Experimental equilibrium times and CR removal.

\begin{tabular}{lcc}
\hline Samples & Equilibrium time $(\mathrm{h})$ & $\begin{array}{c}\text { CR removal } \\
(\%)\end{array}$ \\
\hline TC & 16 & 86 \\
RF & 24 & 98 \\
TC/Coal & 80 & 83 \\
RF/Coal & 90 & 81 \\
RF/BWM & 24 & 87 \\
\hline
\end{tabular}


Table 6. Comparison of the first-order and pseudo second- order kinetics models of CR adsorption.

\begin{tabular}{lccccccc}
\hline \multirow{2}{*}{ Sample } & & \multicolumn{2}{c}{ First-order kinetic model } & \multicolumn{2}{c}{ Second-order kinetic model } \\
\cline { 3 - 8 } & $q_{\text {e exp }}$ & $k_{1}$ & $q_{e}$ & $R^{2}$ & $k_{2}$ & $q_{e}$ & $R^{2}$ \\
& $(\mathrm{mg} / \mathrm{g})$ & $\left(\mathrm{dm}^{3} / \mathrm{min}\right)$ & $(\mathrm{mg} / \mathrm{g})$ & & $(\mathrm{g} / \mathrm{mg} \mathrm{min})$ & $(\mathrm{mg} / \mathrm{g})$ & \\
\hline TC & 87 & 0.0014 & 58 & 0.765 & $3.1 \cdot 10^{-5}$ & 96 & 0.989 \\
RF & 99 & 0.0006 & 21 & 0.305 & $3.7 \cdot 10^{-4}$ & 94 & 0.997 \\
TC/Coal & 83 & 0.0007 & 56 & 0.967 & $2.7 \cdot 10^{-5}$ & 88 & 0.994 \\
RF/Coal & 81 & 0.0003 & 67 & 0.962 & $1.0 \cdot 10^{-5}$ & 90 & 0.947 \\
RF/BWM & 87 & 0.0009 & 60 & 0.734 & $3.7 \cdot 10^{-5}$ & 90 & 0.982 \\
\hline
\end{tabular}


Table 7. Equilibrium isotherm models for CR adsorption.

\begin{tabular}{lcccccc}
\hline Sample & \multicolumn{3}{c}{ Langmuir } & \multicolumn{3}{c}{ Freundlich } \\
\cline { 2 - 7 } & $\begin{array}{c}\mathrm{q}_{\max } \\
(\mathrm{mg} / \mathrm{g})\end{array}$ & $\begin{array}{c}\mathrm{b} \\
\left(\mathrm{dm}^{3} / \mathrm{g}\right)\end{array}$ & $\mathrm{R}^{2}$ & $\begin{array}{c}\mathrm{K}_{\mathrm{f}} \\
\left(\mathrm{mg}^{1-\mathrm{n}} \mathrm{dm}^{3 \mathrm{n}} / \mathrm{g}\right)\end{array}$ \\
\hline TC & 159 & 0.57 & 0.998 & 65 & 0.275 & 0.939 \\
$\mathrm{RF}$ & 200 & 2.08 & 0.999 & 108 & 0.224 & 0.902 \\
TC/Coal & 139 & 0.83 & 0.992 & 73 & 0.180 & 0.952 \\
RF/Coal & 120 & 0.09 & 0.965 & 20 & 0.439 & 0.888 \\
RF/BWM & 83 & 0.45 & 0.981 & 47 & 0.135 & 0.954 \\
\hline
\end{tabular}




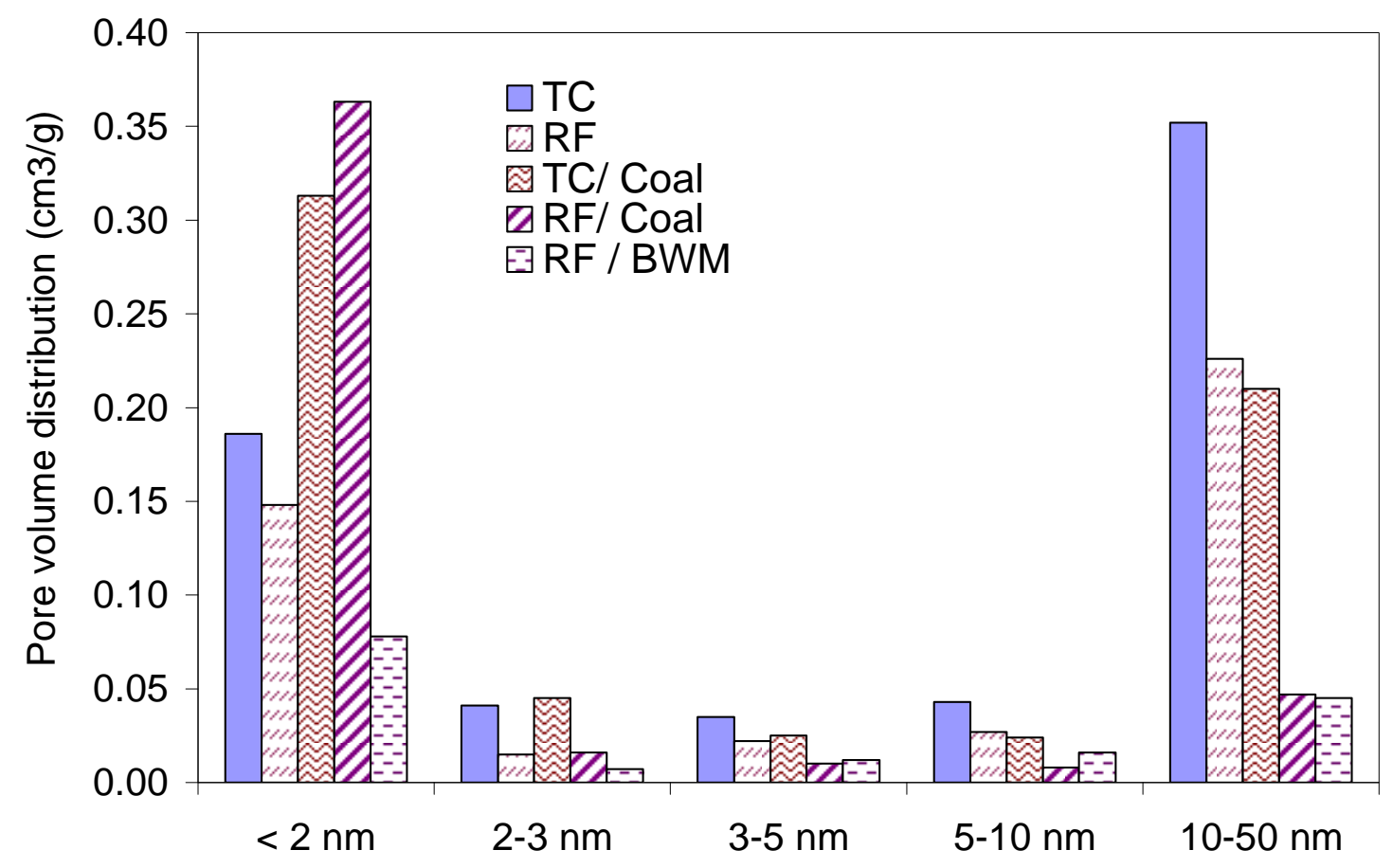

Figure 1. Pore volume distribution of the ACs prepared from TC, RF and their blends with coal and BWM. 
a.
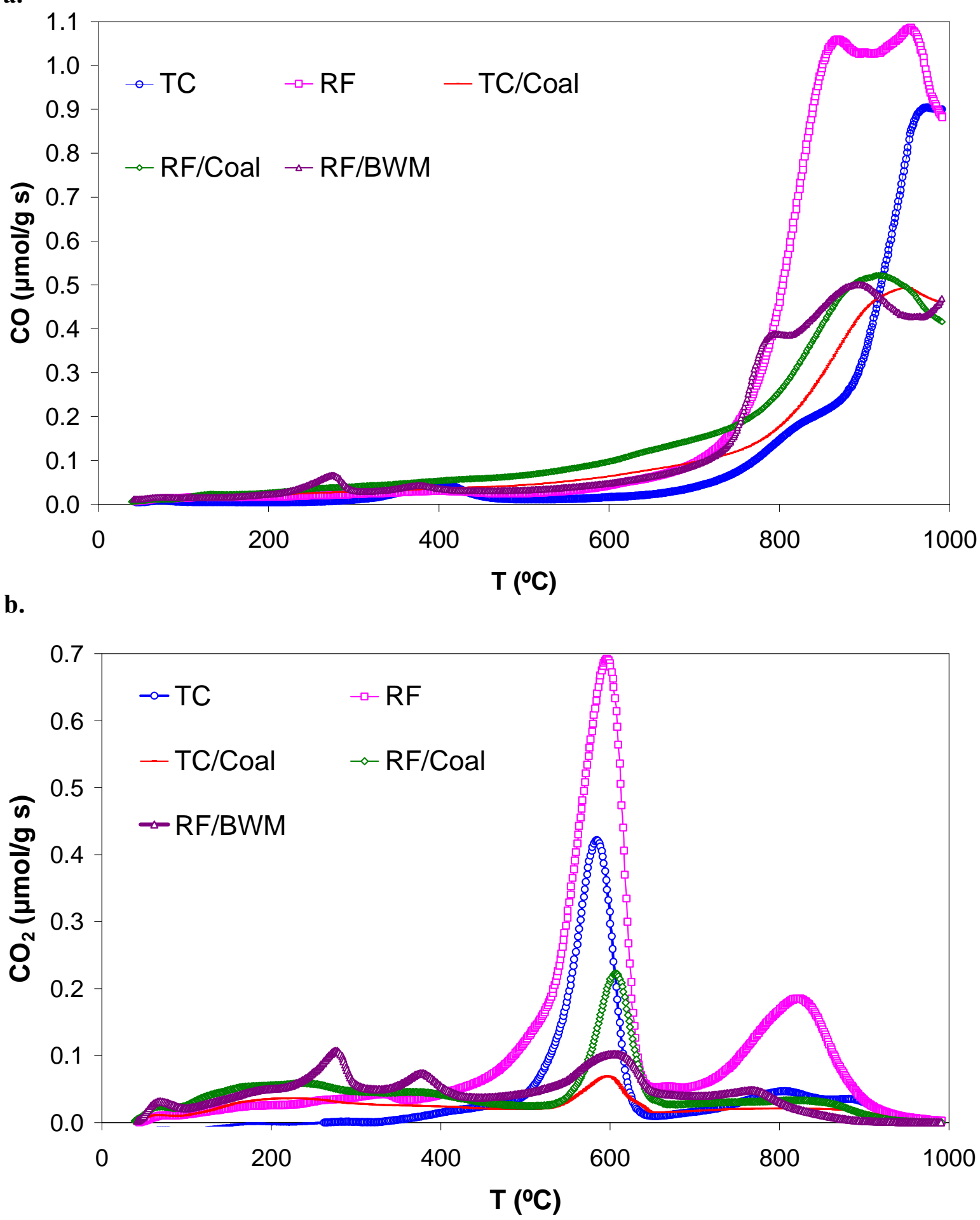

Figure 2. TPD $\mathrm{CO}(\mathrm{a})$ and $\mathrm{CO}_{2}(\mathrm{~b})$ spectra corresponding to the ACs. 


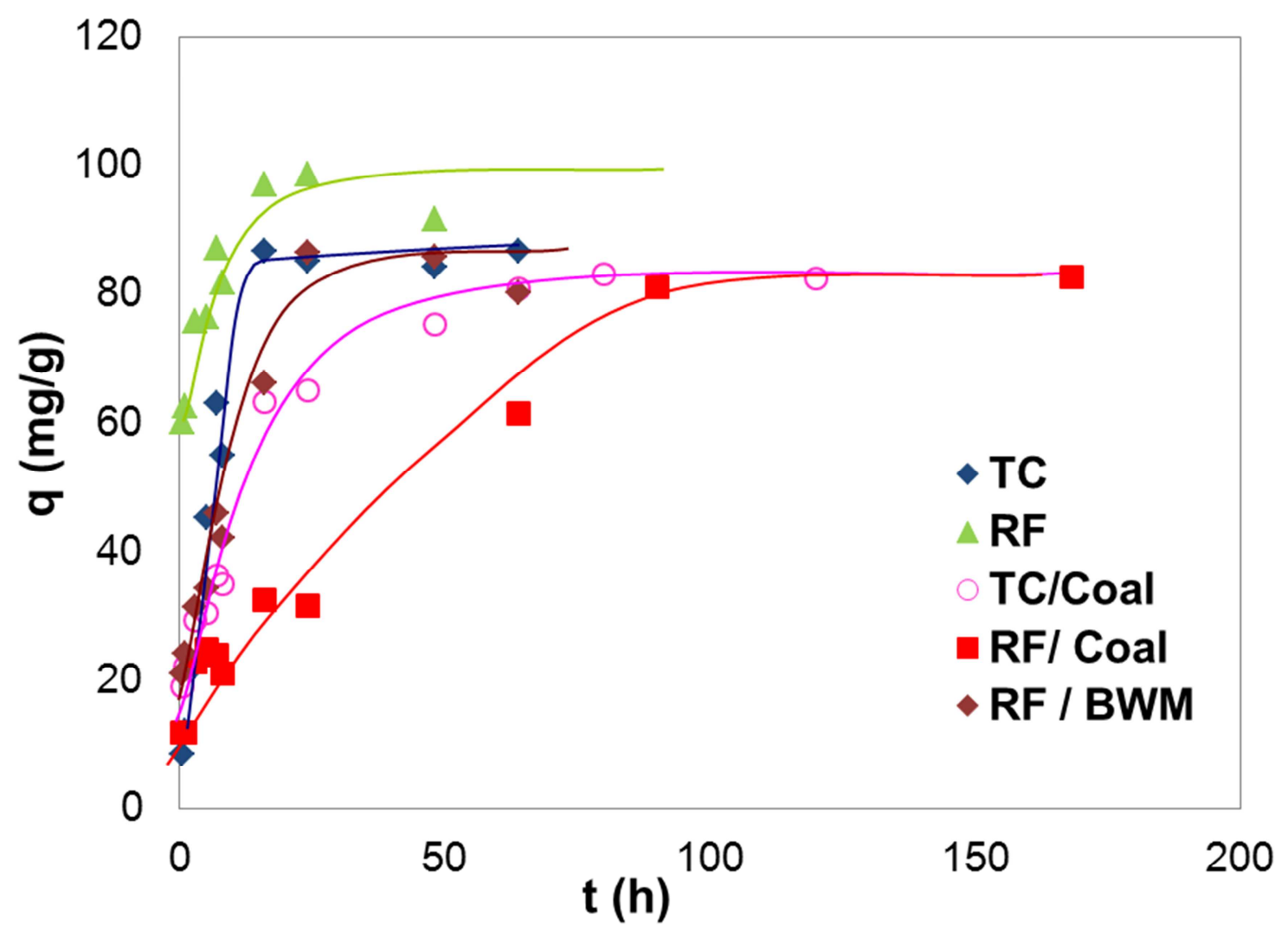

Figure 3. Effect of contact time on the removal of CR. 


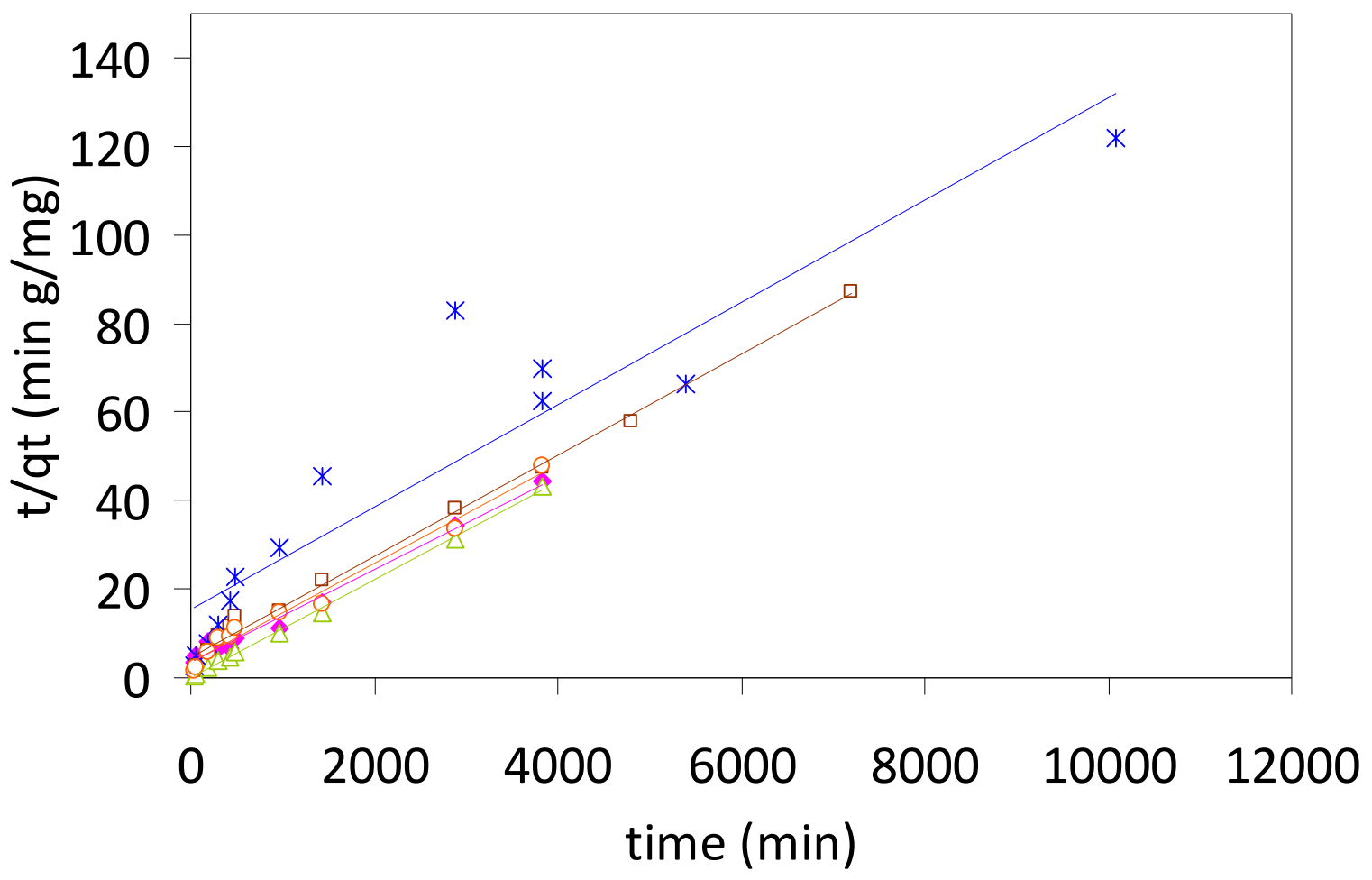

Figure 4. Results of the $\mathrm{CR}$ pseudo-second order adsorption kinetic model for the ACs: $\circ \mathrm{TC}, \bullet \mathrm{RF}, \triangle \mathrm{TC} /$ Coal, $\square \mathrm{RF} /$ Coal, $* \mathrm{RF} / \mathrm{BWM}$. 

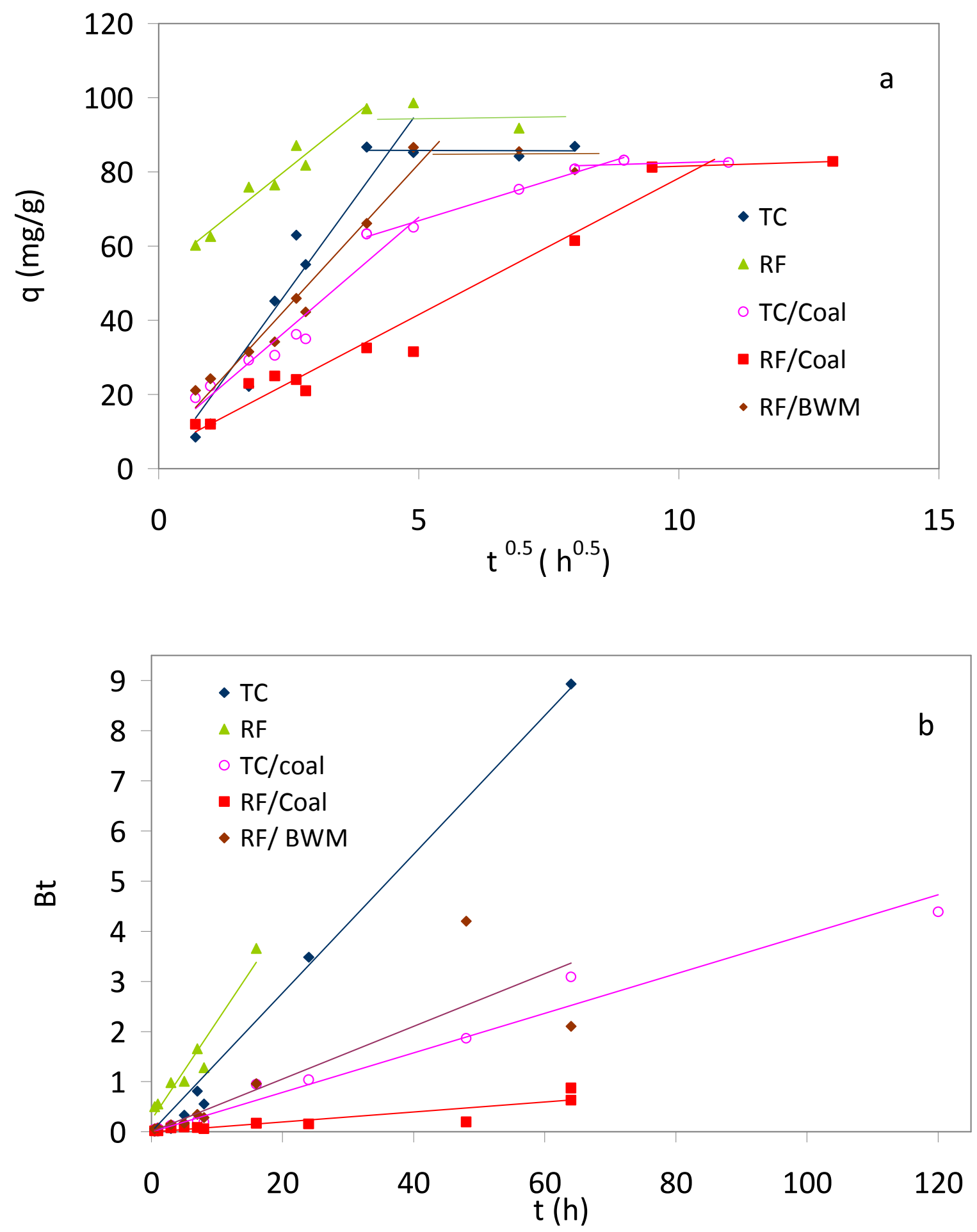

Figure 5. Intraparticle diffusion (a) and Boyd model (b) for the adsorption of CR on ACs. 


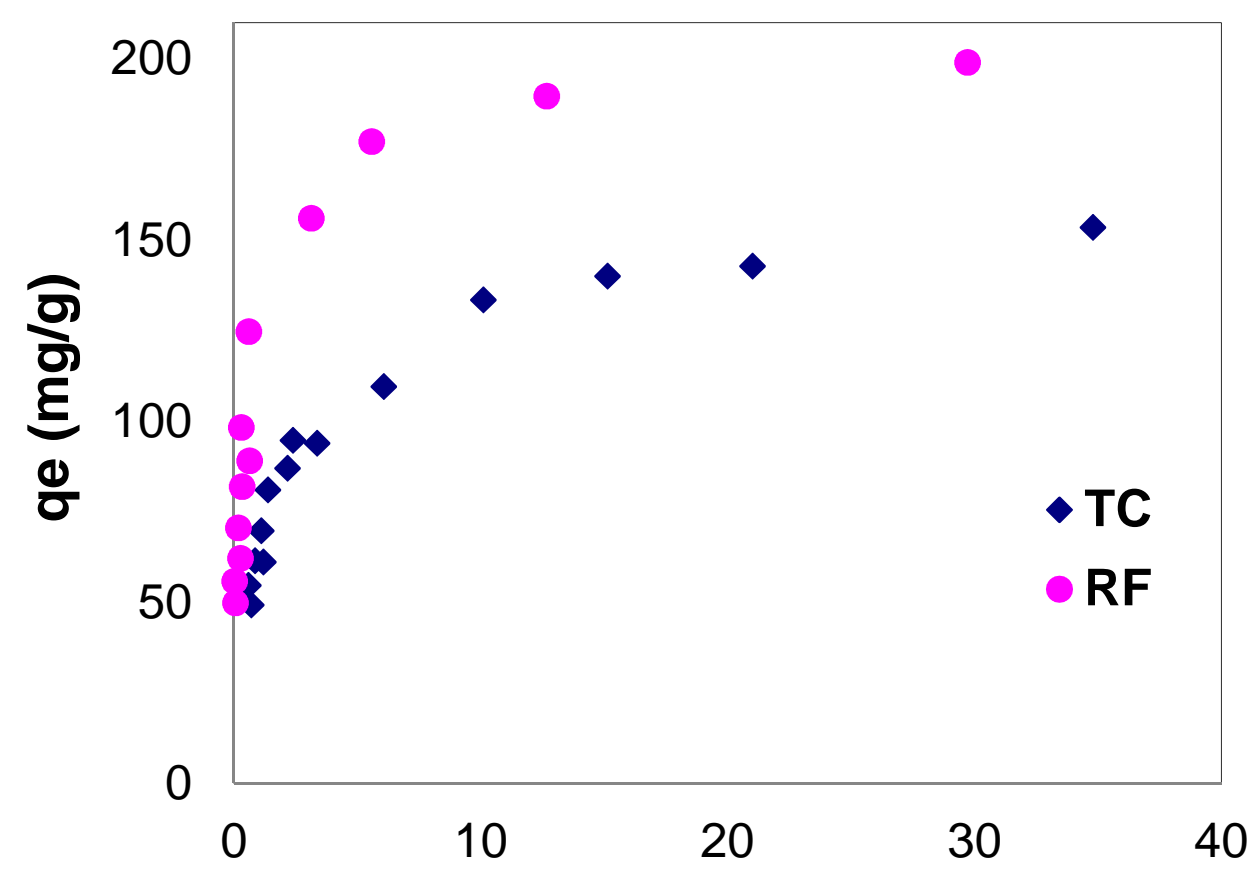

$\mathrm{Ce}\left(\mathrm{mg} / \mathrm{dm}^{3}\right)$

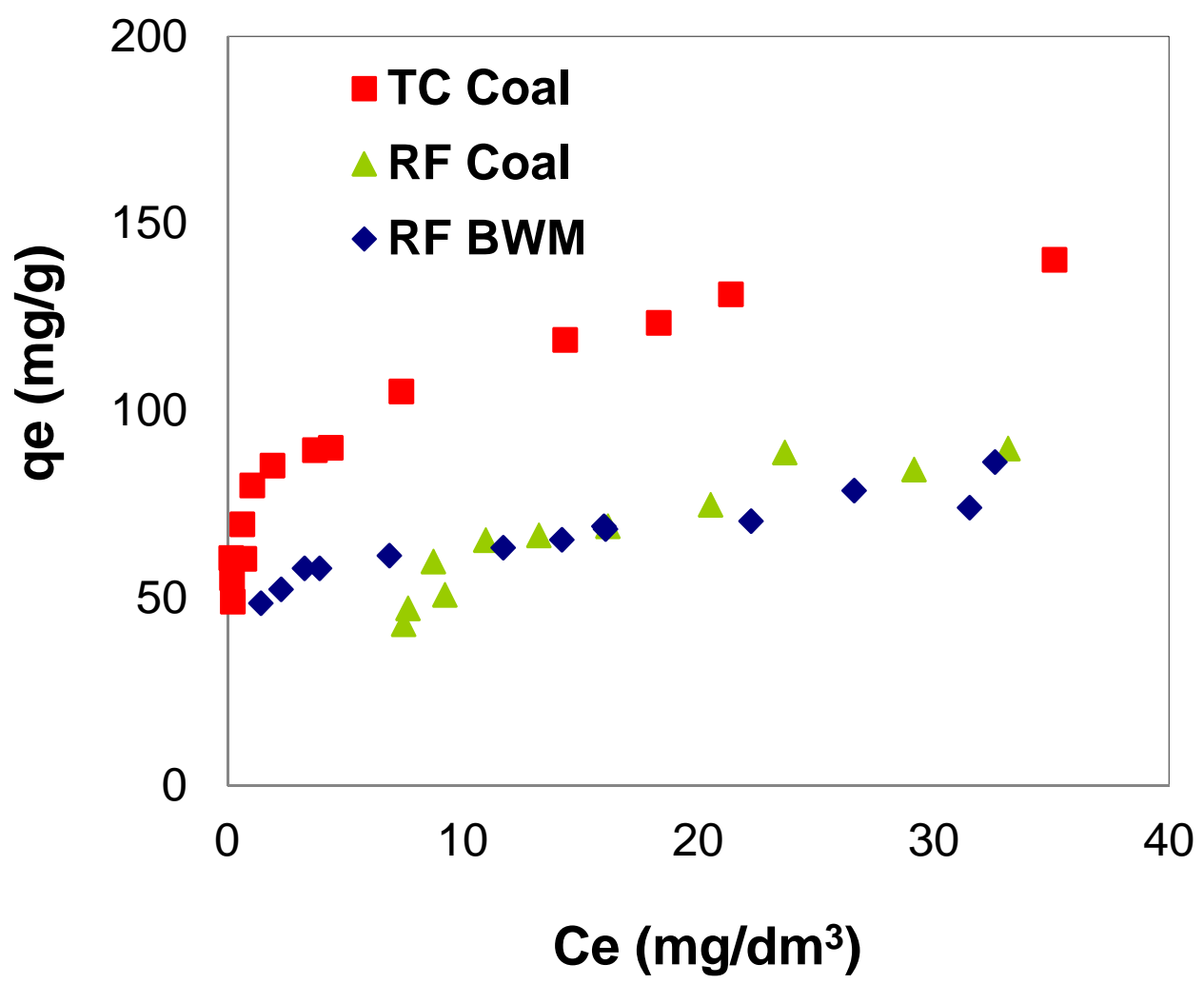

Figure 6. Equilibrium adsorption isotherms for the adsorption of CR on ACs. 